\title{
Modeling and Simulation of the Single Grain Grinding Process of the Nano-Particle Jet Flow of Minimal Quantity Lubrication
}

\author{
Sheng Wang, Changhe Li*, Xiaowei Zhang, Dongzhou Jia, Dongtun Zhang and Qiang Zhang
}

\author{
School of Mechanical Engineering, Qingdao Technological University, 266033 Qingdao, China
}

\begin{abstract}
Along with strengthening of people's environmental protection awareness, the MQL technology has been used in grinding, but its limited cooling effect cannot satisfy the requirement of heat transfer enhancement in the grinding area. The new technology of nano-particle jet flow of MQL can effectively solve the heat transfer in the grinding zone and enhance the lubrication characteristics as well. This paper studies mainly the grinding process of the single grain under the condition of the nano-particle jet flow of MQL by establishing the kinematics model, elastic deformation model and plastic accumulation model of the single grain and simulating the value of the surface topography of the single-grain grinding workpiece with quenching $45 \#$ as the research subject. The results show that the grinding depth will exert a certain influence over the material deformation on the surface of the workpiece, the pile height and the length of the grinding crack. The yielding amount of the grain center $\delta c$ and the elastic recovery amount of the materials on the surface of the workpiece $\delta \mathrm{w}$ increases with the grinding depth. The height of the material accumulation increases with the grinding depth. Furthermore, the change amplitude is large and the change gradient decreases correspondingly. The length of the grinding crack increases with the grinding depth, and the grinding depth and the height of the material accumulation have an approximate linear relationship.
\end{abstract}

Keywords: Grinding process, minimal quantity lubrication, nano-particle, single grain.

\section{INTRODUCTION}

With the low material removal rate, grinding can be used to obtain high-precision and high-surface-quality work pieces and can thus be widely applied in mechanical processing $[1,2]$. However, great heat is produced in the process of grinding which affects the surface quality of the work pieces, so the generally used cooling and lubrication method in the industrial production is the pouring grinding [3-5]. This cooling and lubrication form is very damaging to the environment and the health of the workers. To protect the environment and reduce the cost, dry grinding without the use of the lubricant has emerged accordingly. Yet, dry grinding can not take away the heat generated in the process of grinding, resulting in the deterioration of the surface quality of the work pieces and a great reduction in the service life of the grinding wheel $[6,7]$.

Minimal quantity lubrication technology (MQL) means using the minimal lubricant on the premise of ensuring the lubrication performance and cooling effect. MQL grinding is to mix minimal lubricants with the high-pressure gas and then make them enter the high-temperature grinding area after the mix atomization of the high-pressure airflow [8]. The high-pressure airflow plays the role of cooling and chip removal. The lubricating oil adheres to the grinding surface of the work piece to form a layer of protective film for MQL [9]. However, studies show that the limited cooling effect of

\footnotetext{
*Address correspondence to this author at the School of Mechanical Engineering, Qingdao Technological University, 266033 Qingdao, China; Tel: +86-532-85071757; Fax: +86-532-85071286;
}

E-mail: sy_lichanghe@163.com the high-pressure airflow can not satisfy the need for the enhanced heat transfer in the high-pressure grinding zone. In addition, the machining quality of the work pieces and the service life of the grinding wheel are significantly lower than those with the traditional pouring grinding, indicating that the MQL technology needs further improvement [10-13].

According to the heat transfer enhancement theory, solids have greater heat transfer capacity than liquids and gases. On this basis, many domestic and foreign scholars [14] have proposed to add the solid nanoparticles into the minimal lubricating oil to improve the defects of the insufficient heat transfer of the minimal lubrication machining. This method is called the nano-particle jet flow of MQL. The relevant studies show that it is helpful for improving the tribological properties of the grinding wheel/workpiece interface, reducing the grinding force and specific grinding energy, improving the insufficient heat transfer and enhancing the lubrication performance of MQL grinding $[15,16]$.

At present, there are two study methods of the surface topography generation process. One is the experimental method and the other is the modeling and simulation method. The former needs a large number of machining experiments. In addition, it just studies the surface topography of the finally generated workpiece but cannot reflect the material removal mechanism in the machining process. The latter models the machining process to fully analyze the influence of various parameters on the machining process, which reveals the removal mechanism and reduces the experiment time. Surface roughness is an important parameter to evaluate the surface topography of the workpiece. Through establishing the relationship between the grinding parameters 
and the surface roughness, it will have certain guidance functions to the optimization of the grinding parameters. The domestic and foreign scholars have conducted much theoretical and experimental research on the prediction of the surface topography generation and surface roughness of the workpieces [17].

Prof. Gong Yadong [18] in Northeastern University uses the simulation technology to realize the simulation of the surface topography generation process of the ground grinding workpiece with $\mathrm{C}++$ programming language and OpenGL graphical tool, and establishes the simulation platform of the surface topography generation. In this method, the surface of the grinding wheel is made of the spherical grinding grains, considering the impact of the grinding wheel parameters and the grinding parameters on the surface topography generation. Dr. Su Chong [19] realizes the simulation of the surface topography generation process with the same method and studies the relationship between different grinding parameters and the surface roughness of the workpieces. The difference is that the cube with different alignment directions is adopted for the adhesive grains on the surface of the grinding wheel in simulation [20].

The Japanese scholar Sakakura [21] measures the section profile of 50 grains and takes them as the standard grain to randomly distribute them on the surface of the grinding wheel, thus realizing the digital simulation of the topography of the grinding wheel [20]. Under the premise of considering the elastic deformation of the grain, he completes the simulation of the surface topography generation process of the external cylindrical grinding workpieces with the grinding wheel and calculates the surface roughness value of the sampling area.

Salisbury et al. [22, 23] in Michigan Technological University sample the surface topography of the grinding wheel with the surface roughness tester and reconstruct the sampled topography to realize the digital simulation of the surface topography of the grinding wheel [24]. They complete the simulation of the surface topography generation process of the workpiece by the use of the topography of the reconstructed grinding wheel and the models related to grinding and evaluate the surface topography of the workpiece. However, the elastic deformation of the grain and the workpiece is not taken into account in the simulation, so it's difficult to simulate the real surface topography generation process of the workpiece.

The Indian scholar Suryarghya [25] adopts the grains in the shape of regular triangular pyramid to generate the surface topography of the grinding wheel according to the uniform distribution. All grains on the surface of the grinding wheel have the same angle and configuration direction [20]. According to the grinding kinematics, the method realizes the simulation of the surface topography generation of the workpiece, calculates the surface roughness value, and studies the influence law of the grinding parameters on the surface roughness as well as the relationship between the surface roughness and the maximum undeformed chip thickness [24, 26, 27]. The research shows that the maximum undeformed chip thickness increases linearly with the increase of the surface roughness value [28].
The American scholar Xunkun Li [29, 30] studies the manufacturing process of the common grinding wheel. He realizes the simulation of the manufacturing process of the grinding wheel mixture, like the mixture of the grains and the binder, grinding wheel modeling, roasting and dressing to generate the surface topography of the common grinding wheel. He also completes the simulation of the surface topography generation process of the workpiece with the grinding wheel and analyzes the grinding force, grinding heat and surface topography [20].

The Canadian scholar X. Zhou [31] makes the grid processing of the $3 \mathrm{D}$ grinding wheel in which the grains are located at each grid point to complete the simulation of the surface topography of the workpiece. According the grinding kinematical theory, he makes the grinding simulation with the grinding wheel, realizes the surface topography generation process of the workpiece with the search method and verifies the surface roughness of the workpiece generated by the simulation with the experiment [24]. The results show that the surface roughness value output by the simulation is less than the experimental value. It's important to note that due to the random simulation of the surface of the grinding wheel, this method is difficult to simulate the grains randomly distributed on the surface of the common grinding wheel [20, 28].

Prof. Tonshoff in the University of Hanover compares the grinding process to the witchcraft in the CIRP report [32]. The grinding system converts the input parameters and the system parameters into various static and dynamic output variables, during which the complex changes will happen. It will be difficult to study the grinding process from the whole system. At the same time, the grains on the surface of the grinding wheel are randomly distributed, which further increases the difficulty of the research [28]. Therefore, the current studies related to the grinding process usually take the single grain as the research subject and then transit to the whole grinding wheel. In view of this, this paper will study the grinding process of the single grain, in order to lay a foundation of the future research.

\section{ESTABLISHMENT OF THE COORDINATE SYSTEM ON THE SURFACE OF THE WORKPIECE}

This paper mainly studies the surface topography of the ground grinding workpiece. To facilitate the establishment of the relevant mathematical model, the coordinate system for the surface of the workpiece is established with the lowest point of contact between the grain and the workpiece as the origin of coordinate, in which the $\mathrm{x}$ axis and the $\mathrm{y}$ axis are the longitudinal direction of feed and the transverse direction of feed of the worktable, respectively, and the $\mathrm{z}$ axis is the radial direction of feed of the grinding wheel, as shown in Fig. (1).

\section{THE KINEMATICS MODEL OF THE SINGLE GRAIN}

Due to the complexity of the grinding process, the simplification of the grinding process is particularly important in the grinding kinematics simulation. Based on the above reasons, the following hypotheses are made [33]:

(1) Ignore the vibration of the grinding wheel; 
(2) When the grain and the surface materials of the workpiece interfere with each other, the materials contacting with the grain are completely removed;

(3) Do not consider the lateral flow and built-up in the process of material removal.

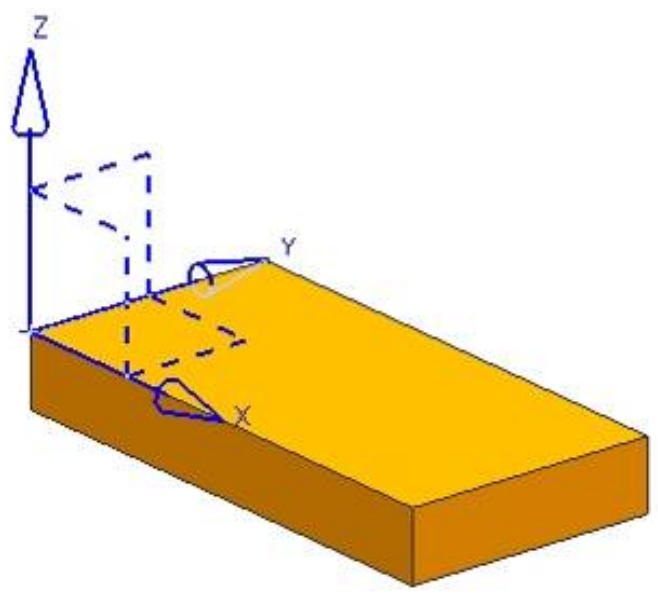

Fig. (1). The coordinate system for the surface of the grinding workpiece.

In the coordinate system $X O Z$, the rectangular coordinate system is established with the lowest point of contact between the grain and the workpiece $O$, as shown in Fig. (2).

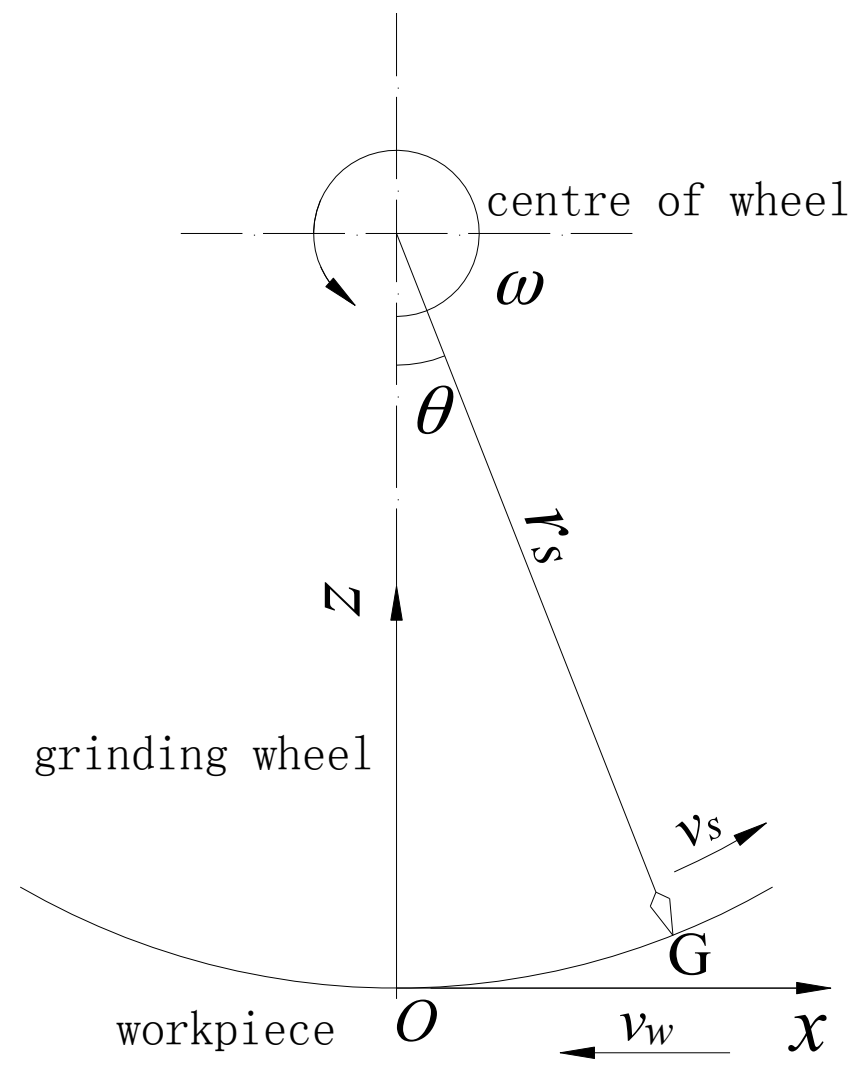

Fig. (2). The trajectory map of the single grain.

The trajectory equation of Grain $G$ can be written as [34]:

$x=v_{w} t+r_{s} \sin \theta$ $z=r_{s}(1-\cos \theta)$

where $v_{w}$ is the feed speed of the workpiece;

$r_{s}$ is the radius of the grinding wheel;

$t$ is the grind time;

$\theta$ is the corner of the grinding wheel. Since $\theta$ is very small, $\sin \theta \approx \theta$ and $\theta^{2}=2(1-\cos \theta)$.

The peripheral velocity of the grinding wheel $v_{s}$ can be expressed as [12]:

$v_{s}=r_{s} \omega$

where $\omega$ is the angular velocity of the grinding wheel.

The corner of the grinding wheel $\theta$ can be expressed as:

$\theta=\omega t$

The grinding time $t$ can be deduced by combining Eq. (3) and (4) and eliminating $\omega$ :

$t=\frac{r_{s} \theta}{v_{s}}$

Substitute Eq. (5) into Eq. (1) to obtain:

$x=r_{s} \theta\left(\frac{v_{w}}{v_{s}}+1\right)$

Substitute $\theta^{2}=2(1-\cos \theta)$ into Eq. (2) to get:

$z=\frac{1}{2} r_{s} \theta^{2}$

The trajectory equation of Grain $G$ is expressed as Eq. (8) by combining Eq. (6) and (7) and eliminating $\theta$.

$$
\frac{z}{x^{2}}=\frac{1}{2 r_{s}\left(\frac{v_{w}}{v_{s}}+1\right)^{2}}
$$

It can be further written as:

$$
z=\frac{x^{2}}{d_{s}\left(\frac{v_{w}}{v_{s}}+1\right)^{2}}
$$

where $d_{s}$ is the diameter of the grinding wheel.

\section{INTERACTION BETWEEN THE GRAIN AND THE WORKPIECE}

\section{Elastic Deformation Model}

The stress status on the single grain normal can be regarded to be the same as that when measuring the Brinell hardness. The deformation process is limited in an elasticplastic deformation boundary. When the sphere moves horizontally, the plastic deformation zone on the surface of the sphere begins to tilt [20]. The workpiece materials accumulate forward and tear to form chips from the surface of the workpiece, as shown in Fig. (3). 


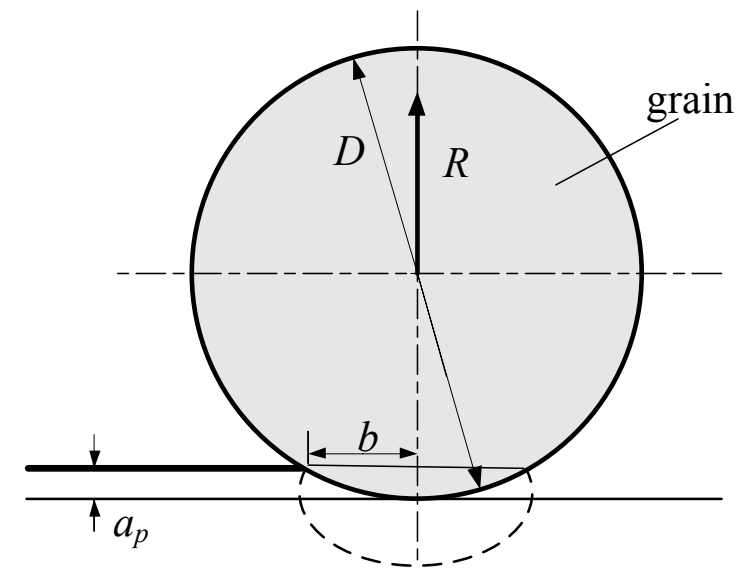

(a)

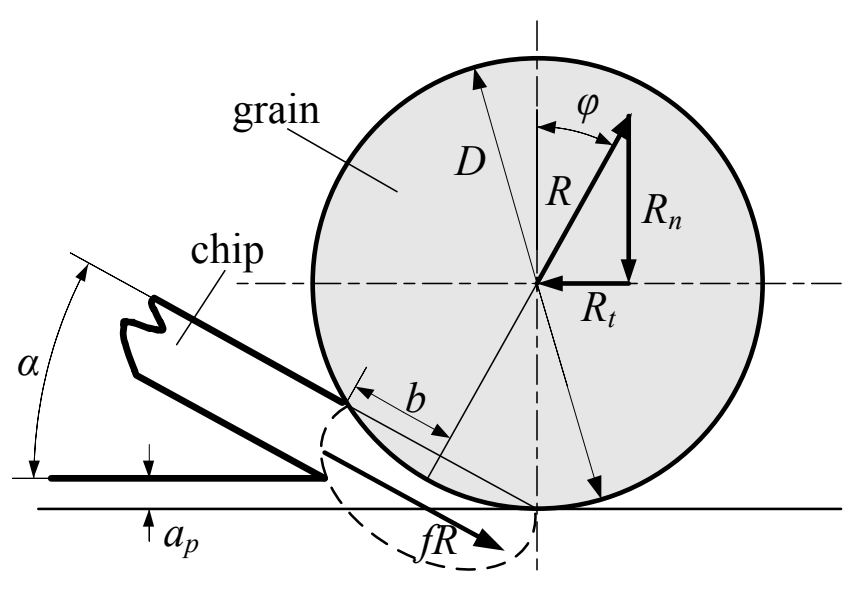

(b)

Fig. (3). The stress analysis model of the single grain, (a) before movement; (b) after movement.

According to the stress analysis of the single grain before movement in Fig. (3a), the positive stress $R$ of the single grain can be obtained by the Brinell hardness test method:

$$
R=\pi b^{2} H\left(C^{\prime} / 3\right)
$$

where $C^{\prime}$ refers to the ratio of the average pressure of the contact zone to the axial stress, being 3 generally.

$b$ refers to the sectional radius of the indentation, which is equal to one half of the grinding width of the grain.

$H$ refers to the Brinell hardness of the workpiece material.

According to the stress analysis of the single grain after movement in Fig. (3b), the tangential and normal grinding forces of the single grain can be expressed as [35]:

$\left\{\begin{array}{l}F_{t}=R(\sin \varphi+f \cos \varphi) \\ F_{n}=R(\cos \varphi-f \sin \varphi)\end{array}\right.$

where $f$ refers to the coefficient of friction between the grain and the workpiece, which is related to the lubricating effect between the grinding wheels. The coefficient of friction of the nano-particle jet flow of MQL is generally between 0.4 and 0.55 ;

$\varphi$ refers to the corner of the grain.

Corner $\varphi$ can be expressed as: $\varphi=\arccos \frac{D-2 a_{p}}{D}$

where $a_{p}$ is the grinding depth of the grain;

$D$ is the diameter of the grain.

In the grinding process, as the grain is elastically supported by the binder, the center of the grain rises under the action of the grinding force, making the actual interfered curve between the grinding wheel and the workpiece higher than the theoretical one. In addition, the surface of the workpiece after grinding will have elastic recovery, leading to the finally formed surface generation curve higher than the actual interfered curve between the grinding wheel and the workpiece, as shown in Fig. (4) [12].

The actual generation curve should add the yielding amount $\delta_{c}$ of the grain center and the elastic recovery amount $\delta_{w}$ based on the theoretical trajectory. The following equation can be obtained after the discretization of the workpiece surface (2D):

$Z_{i}=z_{i}+\delta_{c i}+\delta_{w i}$

where $Z_{i}$ is the actual coordinate value of the workpiece surface at the $i^{\text {th }}$ point after the grain cuts the workpiece;

$z_{i}$ is the theoretical coordinate value of the workpiece surface at the $\mathrm{i}^{\text {th }}$ point after the grain cuts the workpiece;

\section{actual interfered curve}

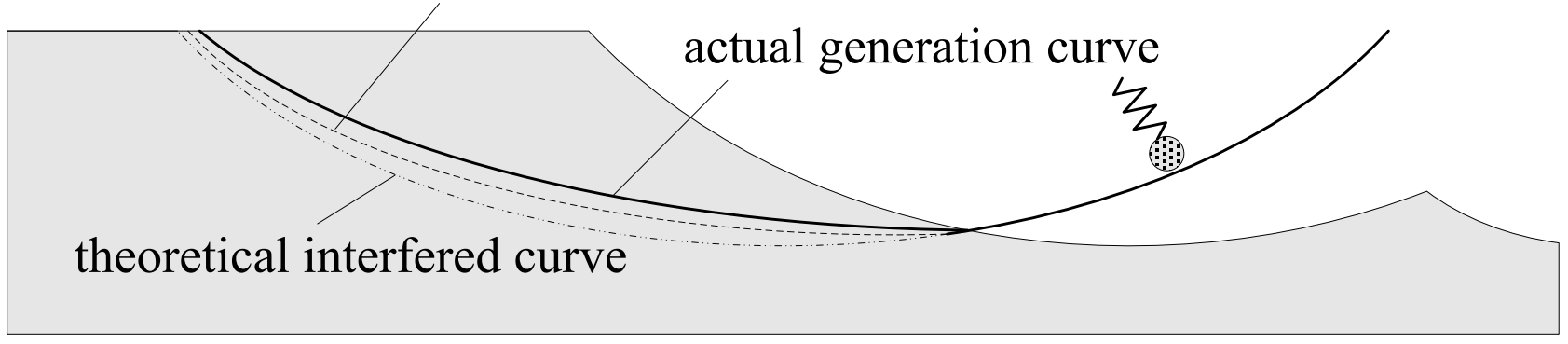

Fig. (4). The action curve between the grain and the workpiece. 
$\delta_{c i}$ is the yielding value of the grain center at the $\mathrm{i}^{\text {th }}$ point;

$\delta_{w}$ is the elastic recovery value of the workpiece at the $i^{\text {th }}$ point.

The yielding amount of the grain center $\delta_{c}$ and the elastic recovery amount of the workpiece $\delta_{w}$ are:

$$
\begin{aligned}
& \delta_{c}=C F_{n}^{2 / 3}=C[R(\cos \theta-f \sin \theta)]^{2 / 3} \\
& \delta_{w}=F_{n} / k=R(\cos \theta-f \sin \theta) / k
\end{aligned}
$$

where $C$ is a constant ranging from 0.08 to 0.25 , being 0.15 on average;

$k$ is the rigidity coefficient of the workpiece.

After calculation, the yielding amount of the grain center $\delta_{c}$ is much less than the elastic recovery amount of the workpiece $\delta_{w}$. The latter plays a leading role.

\section{Plastic Accumulation Model}

Only the undeformed workpiece materials are removed by the grains in the grinding process and the rest are piled up on both sides of the grains after the elastic deformation. Thus, a cutting efficiency $\beta$ can be introduced to quantify the accumulation degree of the material. It's defined as the ratio of the volume of the removed undeformed materials to the total grinding volume of the grains [20]. The diagram of the plastic accumulation model is shown in Fig. (5).

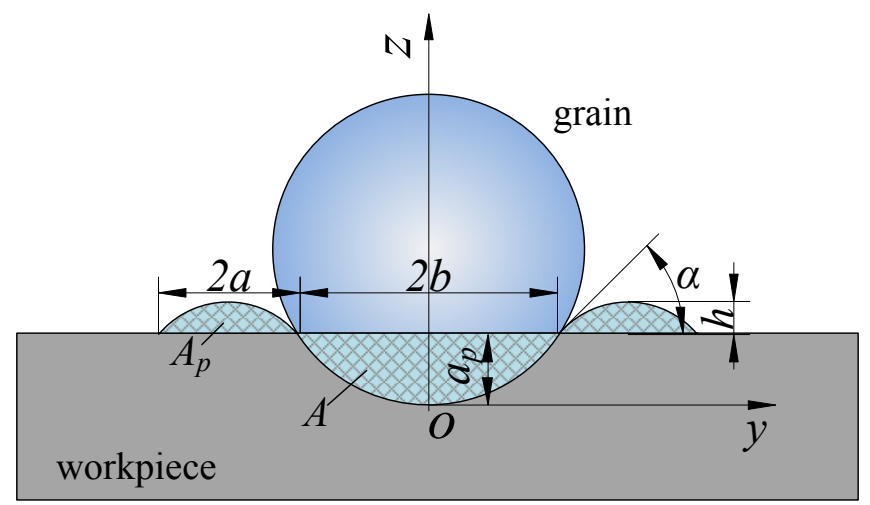

Fig. (5). Plastic accumulation model.

The area of the materials having the elastic deformation and being piled up on both sides of the grains $A_{p}$ is

$$
A_{p}=\frac{(1-\beta) A}{2}
$$

where $A$ refers the volume of the removed material.

Within the workpiece surface coordinate system YOZ, the rectangular coordinate system is established with the lowest point of contact between the grains and the workpiece as the origin of coordinate $O$. The outlines equation of the hemisphere is:

$$
z=\frac{D}{2}-\sqrt{\left(\frac{D}{2}\right)^{2}-y^{2}}
$$

where $D$ is the diameter of the grain.

Setting the grinding width of the grain to be $2 b, b$ is
$b=\sqrt{\left(\frac{D}{2}\right)^{2}-\left(\frac{D}{2}-a_{p}\right)^{2}}$

The shape of the materials piling up on both sides of the grains can be approximately regarded as a parabola. The local coordinate system is established with the intersection point of the parabola axis and the workpiece surface as the origin. At the same time, the materials of the workpiece are set to pile up on both sides along with the direction of Angle $\alpha$. The depth of section of the materials piling up on the surface of the workpiece is $h$ and the width is $2 a$. The equation of the parabola in the local coordinate system is:

$z_{1}=h-\frac{h y_{1}^{2}}{a^{2}}$

The outlines equation in the global coordinate system is:

$z=a_{p}+h-\frac{h(y-a-b)^{2}}{a^{2}}$

The area of the removed materials $A$ is:

$A=\frac{\alpha D^{2}}{2}-\frac{D b}{2}+b a_{p}$

The area of the piled materials $A_{p}$ is:

$A_{p}=4 a h / 3$

As the workpiece materials pile up on both sides along with the direction Angle $\alpha$, in the local coordinate system, the tangent slope $k$ at the left intersection point of the parabola and the $y 1$ axis should be:

$k=2 h / a=\tan \alpha$

Thus, the values of a and $\mathrm{h}$ can be deduced as:

$a=\sqrt{\frac{3 A_{p}}{2 \tan \alpha}}$
$h=\sqrt{\frac{3 A_{p} \tan \alpha}{8}}$

where $\tan \alpha=\mathrm{a}_{\mathrm{p}} / \mathrm{b}$.

\section{THE SURFACE TOPOGRAPHY MATRIX OF THE WORKPIECE}

The height of any point on the surface of the workpiece is set to be $z_{m n}$, so the surface topography matrix of the workpiece is:

$Z\left(z_{m n}\right)=\left[\begin{array}{cccc}z_{11} & z_{12} & \cdots & z_{1 n} \\ z_{21} & z_{22} & \cdots & z_{2 n} \\ \vdots & \vdots & \ddots & \vdots \\ z_{m 1} & z_{m 2} & \cdots & z_{m n}\end{array}\right]$

where $m$ and $n$ refer to the number of the discrete points along with the width direction and the length direction of the workpiece, respectively. 


\section{SIMULATION OF THE GRINDING PROCESS OF THE SINGLE GRAIN}

According to the kinematics model, geometric model, elastic deformation model and plastic accumulation model of the single grain established above, the ground grinding process of the single grain is programmed with the MATLAB programming language to realize the simulation analysis of the process through the numerical calculation of the computer.

\section{Simulation Parameter}

The simulation parameters adopted in the simulation of the grinding process of the single grain include the parameters of the grinding wheel, workpiece and grinding, as shown in Tables 1-3, respectively.

Table 1. Parameters of the grinding wheel.

\begin{tabular}{|c|c|}
\hline $\begin{array}{c}\text { Diameter of the } \\
\text { Grinding Wheel } \boldsymbol{d}_{\boldsymbol{s}}\end{array}$ & $\begin{array}{c}\text { Diameter of the Grain } \\
\boldsymbol{D}\end{array}$ \\
\hline \hline $300 \mathrm{~mm}$ & $196 \mu \mathrm{m}$ \\
\hline
\end{tabular}

Table 2. Parameters of the workpiece.

\begin{tabular}{|c|c|c|}
\hline $\begin{array}{c}\text { Material } \\
\text { Type }\end{array}$ & $\begin{array}{c}\text { Rockwell } \\
\text { Hrdness }\end{array}$ & $\begin{array}{c}\text { Stiffness Coefficient } \\
\boldsymbol{k}\end{array}$ \\
\hline \hline Quenching 45\# Steel & $\mathrm{HRC}=45$ & $300 \mathrm{~kg} / \mathrm{mm}$ \\
\hline
\end{tabular}

Table 3. Grinding parameters.

\begin{tabular}{|c|c|c|}
\hline $\begin{array}{c}\text { Peripheral Velocity of the } \\
\text { Grinding Wheel } \boldsymbol{v}_{\boldsymbol{s}}\end{array}$ & $\begin{array}{c}\text { Feed Rate of the } \\
\text { Worktable } \boldsymbol{v}_{\boldsymbol{w}}\end{array}$ & $\begin{array}{c}\text { Grinding Depth } \\
\boldsymbol{a}_{\boldsymbol{p}}\end{array}$ \\
\hline \hline $30 \mathrm{~m} / \mathrm{s}$ & $0.05 \mathrm{~m} / \mathrm{s}$ & $5 \sim 40 \mu \mathrm{m}$ \\
\hline
\end{tabular}

\section{Simulation Program Flow}

Fig. (6) shows the simulation program flow chart of the grinding process of the single grain. The specific simulation flow is: input the grinding simulation parameters of the single grain and initialize the simulation process first; then, solve the motion trajectory of the single grain in the $3 \mathrm{D}$ space according to the kinematics model and calculate the coordinate matrix for the workpiece surface after grinding by the grain; calculate the coordinate matrix for the workpiece surface after the elastic and plastic deformation according to the elastic deformation model and the plastic accumulation model, and finally output the simulation results.

\section{Simulation Result Analysis}

Fig. (7) presents the surface topography of the workpiece after grinding by the single grain output when the peripheral velocity of the grinding wheel is $30 \mathrm{~m} / \mathrm{s}$, the feed speed of the workpiece is $0.05 \mathrm{~m} / \mathrm{s}$ and the grinding depth is $20 \mu \mathrm{m}$. It can be seen from the figure that a parabolic abrasive mark at about $2.4 \mathrm{~mm}$ long is generated on the surface of the workpiece after grinding by the single grain. The obvious

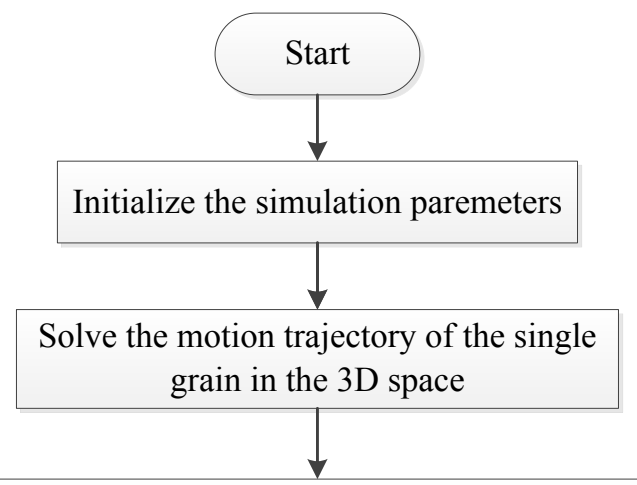

Calculate the coordinate matrix for the workpiece surface after grinding by the grain

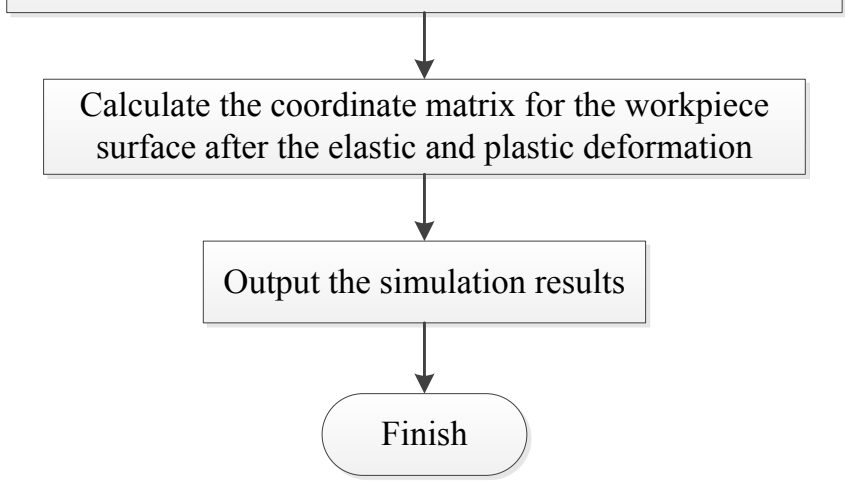

Fig. (6). The grinding simulation program flow chart of the single grain.

material piling phenomenon is produced on both sides of the abrasive mark. The maximum material piling height of the workpiece output by the simulation is $4.82 \mathrm{~mm}$. With the motion of the grain on the surface of the workpiece, the piling height reduces accordingly until to 0 ; with the above grinding parameters, the theoretical grinding depth is $20 \mu \mathrm{m}$ while the actual maximum grinding depth output by simulation is $19.12 \mu \mathrm{m}$, a decrease of $0.88 \mu \mathrm{m}$, indicating that the elastic-plastic deformation on the surface of the workpiece will have great influence on the surface topography.

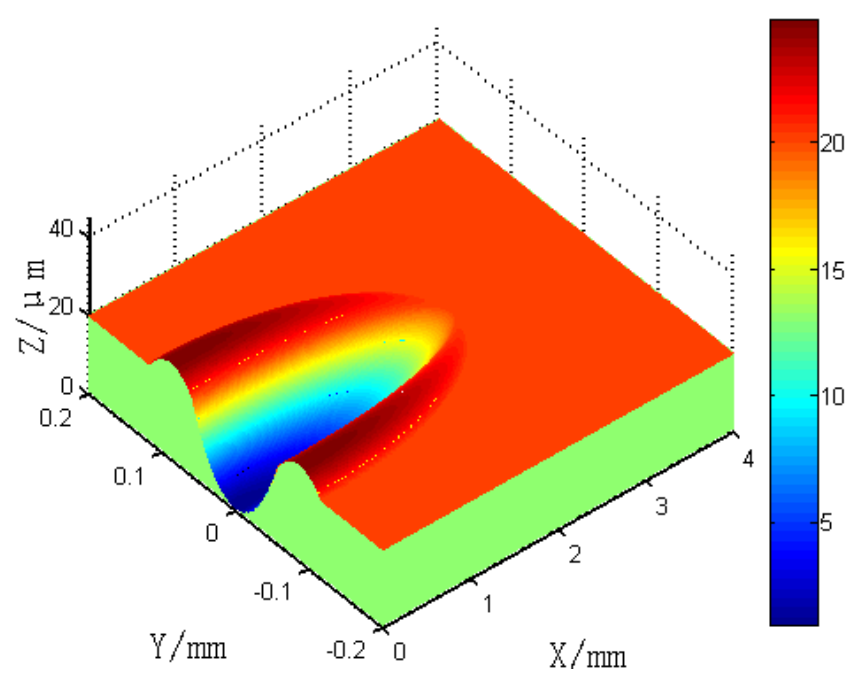

Fig. (7). The surface topography of the workpiece after grinding by the single grain. 
It can be seen from the mathematical model that the grinding depth has a great influence on the total deformation amount $\delta$ and piling height $h$ of the surface material of the workpiece and the length of the grinding crack $l$. In order to study the influence of the grinding depth on the above variables, this paper makes the corresponding simulation research. Fig. (8) shows the relationship curve between different grinding depths and the deformation amount of the materials on the surface of the workpiece. It can be seen that when the grinding depth rises from $5 \mu \mathrm{m}$ to $40 \mu \mathrm{m}$, the yielding amount of the grain center changes from $0.16 \mu \mathrm{m}$ to $0.59 \mu \mathrm{m}$. The changing amplitude is small and the gradient reduces. The elastic recovery amount of the workpiece $\delta_{w}$ changes from $0.41 \mu \mathrm{m}$ to $2.67 \mu \mathrm{m}$. The changing amplitude is large and the gradient reduces. The total deformation amount changes from $0.58 \mu \mathrm{m}$ to $3.26 \mu \mathrm{m}$. It's because that with the increasing grinding depth, the positive pressure of the single grain rises, and the normal grinding force also increases accordingly, so do the yielding amount of the grain center and the elastic recovery amount of the workpiece.

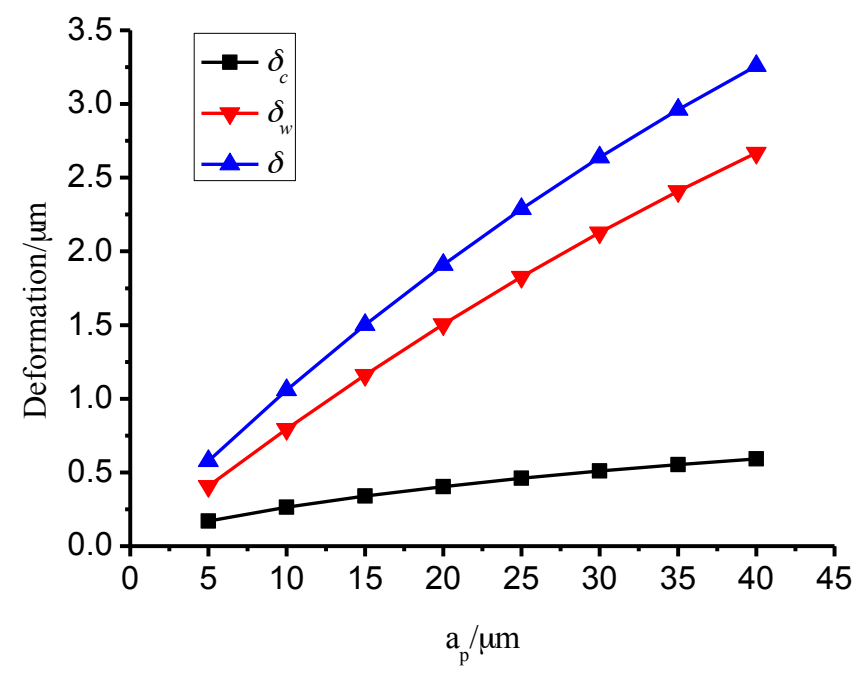

Fig. (8). The relationship between different grinding depths and the deformation amount of the materials on the surface of the workpiece.

Fig. (9) shows the relationship curve between different grinding depth and the grinding crack. It can be seen that when the grinding depth changes from $5 \mu \mathrm{m}$ to $40 \mu \mathrm{m}$, the length of the grinding crack $l$ increases from $1.23 \mu \mathrm{m}$ to $3.47 \mu \mathrm{m}$. The changing amplitude is large and the gradient decreases accordingly. It's because that the increasing grinding depth makes the undeformed cutting thickness of the single grain increase, which further causes the length of the grinding crack rise. At the same time, the grinding depth and the undeformed cutting thickness show an exponential relationship, so the changing gradient decreases.

Fig. (10) presents the relationship curve between different grinding depths and material accumulation height. It can be seen that when the grinding depth changes from $5 \mu \mathrm{m}$ to $40 \mu \mathrm{m}$, the length of the grinding crack $l$ increases from $1.11 \mu \mathrm{m}$ to $9.39 \mu \mathrm{m}$. The grinding depth and the material accumulation height have a linear relationship appropriately. It's because that the increasing grinding depth makes the volume of materials removed by the single grain enlarge and the volume of materials piled up on both sides of

the grinding crack enlarges, too. Then, the height of accumulation rises accordingly.

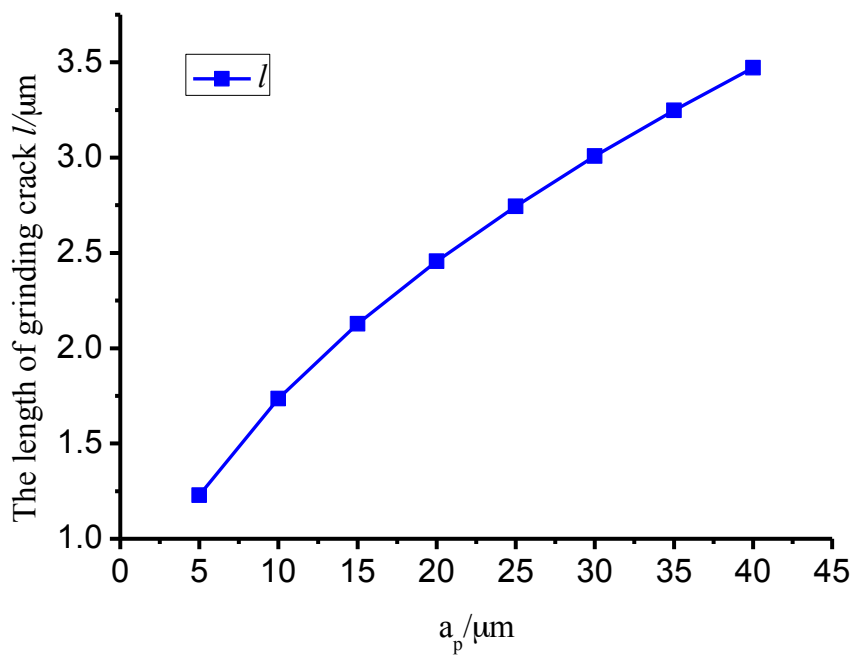

Fig. (9). The relationship between different grinding depths and the length of the grinding crack.

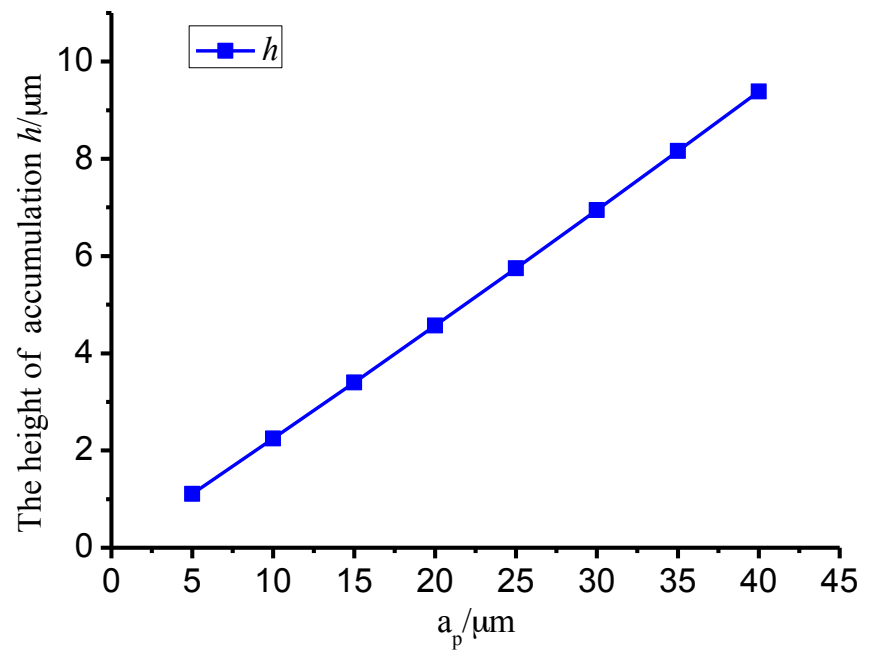

Fig. (10). The relationship between different grinding depths and the height of accumulation.

\section{CONCLUSION}

This paper studies the ground grinding process of the single grain. By establishing the kinematics model, elastic deformation model and plastic accumulation model of the single grain, it researches the surface topography of the workpiece grinded by the single grain. The results show that:

(1) The obvious material accumulation phenomenon produces on both sides of the grinding crack after grinding by the single grain. At the same time, the elastic-plastic deformation happens to the materials on the surface of the workpiece at the grinding point. The deformation can not be ignored when studying the surface topography of the workpiece.

(2) The yielding amount of the grain center $\delta_{c}$ and the elastic recovery amount of the materials on the surface of the workpiece $\delta_{w}$ increase with the grinding depth. The increase amplitude of the yielding amount is small and 
that of the elastic recovery amount is large. The latter plays a leading role.

(3) The height of the material accumulation increases with the grinding depth. The change amplitude is large and the change gradient decreases correspondingly.

(4) The length of the grinding crack increases with the grinding depth. The grinding depth and the height of the material accumulation have an linearly relationship approximately.

\section{CONFLICT OF INTERESTS}

The authors confirm that this article content has no conflicts of interest.

\section{ACKNOWLEDGEMENTS}

This research was financially supported by the National Natural Science Foundation of China (51175276) and Qingdao science and technology program of basic research projects (14-2-4-18-jch).

\section{REFERENCES}

[1] Nguyen T A, Butler D L. Simulation of precision grinding process, part 1: generation of the grinding wheel surface. Int J Mach Tool Manu 2005; 45(11): 1321-8.

[2] Brinksmeier E, Mutlugünes $\mathrm{Y}$, Klocke $\mathrm{F}$, et al. Ultra-precision grinding. CIRP Ann Manuf Technol 2010; 59(2): 652-71

[3] $\mathrm{Xu} \mathrm{X}$, Malkin S. Comparison of methods to measure grinding temperatures. J Manu Sci Eng 2001; 123(2): 191-5.

[4] Barczak LM, Batako ADL, Morgan MN. A study of plane surface grinding under minimum quantity lubrication (MQL) conditions. Int J Mach Tool Manu 2010; 50(11): 977-85.

[5] Heinemann R, Hinduja S, Barrow G, et al. Effect of MQL on the tool life of small twist drills in deep-hole drilling. Intl J Mach Tools Manu 2006; 46(1): 1-6.

[6] Jin T, Stephenson DJ. A study of the convection heat transfer coefficients of grinding fluids. CIRP Ann Manuf Tech 2008; 57(1): $367-70$.

[7] Malkin S, Guo C. Thermal analysis of grinding. CIRP Ann Manuf Technol 2007; 56(2): 760-82.

[8] Davim J P, Sreejith P S, Gomes R, et al. Experimental studies on drilling of aluminium (AA1050) under dry, minimum quantity of lubricant, and flood-lubricated conditions. Proc Inst Mech Eng B J Eng Manuf 2006; 220(10): 1605-11.

[9] Khan MMA, Mithu MAH, Dhar NR. Effects of minimum quantity lubrication on turning AISI 9310 alloy steel using vegetable oilbased cutting fluid. J Mat Process Technol 2009; 209(15): 5573-83.

[10] Sadeghi M H, Haddad M J, Tawakoli T, et al. Minimal quantity lubrication-MQL in grinding of Ti-6Al-4V titanium alloy. Int $\mathrm{J}$ Adv Manuf Tech 2009; 44(5-6): 487-500.

[11] Weinert K, Inasaki I, Sutherland J W, et al. Dry machining and minimum quantity lubrication. CIRP Ann Manuf Technol 2004; 53(2): 511-37

[12] Li C H, Han Z L, Zhang Q, et al. Modeling and Experimental Investigation of Pressure Field in the Grinding Zone with Nanoparticle Jet of MQL. Adv Mech Eng 2013; 2013.

[13] Li C H, Li J Y, Wang S, et al. Modeling and numerical simulation of the grinding temperature field with nanoparticle jet of MQL. Adv Mech Eng 20132013.
[14] Wen D, Lin G, Vafaei S, et al. Review of nanofluids for heat transfer applications. Particuology 2009; 7(2): 141-50.

[15] Choi C, Jung M, Choi Y, et al. Tribological properties of lubricating oil-based nanofluids with metal/carbon nanoparticles. J Nanosci Nanotech 2011; 11(1): 368-71.

[16] Hwang Y, Park H S, Lee J K, et al. Thermal conductivity and lubrication characteristics of nanofluids. Curr Appl Phys 2006; 6: e67-e71.

[17] Brinksmeier E, Aurich J C, Govekar E, et al. Advances in modeling and simulation of grinding processes. CIRP Ann Manuf Technol 2006; 55(2): 667-96.

[18] Gong Y D, Wang B, Wang W S. The simulation of grinding wheels and ground surface roughness based on virtual reality technology. J Mat Process Tech 2002; 129(1): 123-6.

[19] Su C, Hou J, Wang W. Research and Development of Simulation System for Virtual Grinding. Comp Sci Comptl Tech 2008; 1: 409412.

[20] Chen X, Brian Rowe W. Analysis and simulation of the grinding process. Part II: Mechanics of grinding. Intl J Mach Tools Manu 1996; 36(8): 883-96.

[21] Sakakura M, Tsukamoto S, Fujiwara T, et al. Visual simulation of the grinding process. Proc Inst Mech Eng B J Eng Manuf 2008; 222(10): 1233-9.

[22] Salisbury E J, Domala V K, Moon K S, et al. A three-dimensional model for the surface texture in surface grinding, part 1: surface generation model. J Manuf Sci Eng 2001; 123(4): 576-81.

[23] Salisbury E J, Domala V K, Moon K S, et al. A three-dimensional model for the surface texture in surface grinding, part 2: grinding wheel surface texture model. J Manf Sci Eng 2001; 123(4): 582-90.

[24] Qi H S, Rowe W B, Mills B. Contact length in grinding: Part 2: Evaluation of contact length models. Proc Inst Mech Eng J J Eng Tribol 1997; 211(1): 77-85

[25] Chakrabarti S, Paul S. Numerical modeling of surface topography in superabrasive grinding. Intl J Adv Manf Tech 2008; 39: 29-38.

[26] Liu K, Li X P, Rahman M, et al. CBN tool wear in ductile cutting of tungsten carbide. Wear 2003; 255(7): 1344-51.

[27] Yin L, Han Y G, Song X F, et al. In vitro study on high rotation deep removal of ceramic prostheses in dental surgery. $\mathrm{J}$ Biomed Mat Res B Appl Biomat 2007; 82(2): 334-45.

[28] Agarwal S, Venkateswara Rao P. Predictive modeling of force and power based on a new analytical undeformed chip thickness model in ceramic grinding. Intl J Mach Tools Manu 2013; 65: 68-78.

[29] Li X, Rong Y. Framework of grinding process modeling and simulation based on microscopic interaction analysis. Robot Comp Integ Manuf 2011; 27(2): 471-8

[30] Li X. Modeling and simulation of grinding processes based on a virtual wheel model and microscopic interaction analysis. Worcester Polytechnic Institute 2010; 4: 38-78.

[31] Zhou X, Xi F. Modeling and predicting surface roughness of the grinding process. Intl J Mach Tools Manu 2002; 42(8): 969-77.

[32] Tönshoff $\mathrm{H} \mathrm{K}$, Friemuth T, Becker J C. Process monitoring in grinding. CIRP Ann Manuf Technol 2002; 51(2): 551-71.

[33] Nguyen T A, Butler D L. Simulation of surface grinding process, part 2: interaction of the abrasive grain with the workpiece. Intl J Mach Tools Manf 2005; 45(11): 1329-36.

[34] Wang S.. Generating mechanism and experimental investigation on surface topography in the grinding process using MQL by Nanopaticles jet. Qingdao, China. Qingdao Technological University 2013.

[35] Li C.H., Wang S., Zhang Q., \& Jia D.Z. Evaluation of minimum quantity lubrication grinding with nano-particles and recent related patents. Rec Pat Nanotechnol 2013; 7(2), 167-81. 